\title{
Pacing of knowledge: Pedagogic code, pedagogic discourse, and teachers' experiences
}

\section{Devika Naidoo}

Department of Education and Curriculum Studies, University of Johannesburg, Johannesburg, South Africa devikan@uj.ac.za

https://orcid.org/0000-0001-7725-0540

(Received: 17 July 2019; accepted: 13 November 2019)

\section{Abstract}

There is sufficient evidence to suggest that post-apartheid curriculum reform has failed to produce the desired equity in performance for South African learners. Research on classroom practice preceding the current Curriculum and Assessment Policy Statement (CAPS; see Department of Basic Education, 2011), showed very slow pacing of knowledge as a cause of poor performance. Among other complex changes the CAPS regulates the pacing of knowledge. Adherence to prescribed CAPS pacing has been enforced in schools via monitoring tools by hierarchical management structures. In this study, I sought to investigate the impact of the new pacing regime on teaching and learning. The study is framed by Bernstein's theory (2004) that pacing carries invisible social class assumptions, and cognitivist theory (Spillane, Reiser, \& Reimer, 2002) that teachers' individual cognition is influenced by situated cognition and policy signals. I ask two questions: "How does the new pacing regime impact the pedagogic code and pedagogic discourse in lessons?" and "What are teachers' views on how the new pacing regime impacts teaching and learning?" Based in a qualitative research design, in-depth interviews with teachers and classroom observations provided the main data sources. Data analysis shows that the strong pacing of knowledge has unintended consequences: the pedagogic code is lexicalized and hence impoverished and pedagogic discourse contains far too little elaboration for slower learners to facilitate acquisition. The curriculum policy on pacing and hierarchical monitoring of enactment of pacing distracts teachers from the pedagogic goal of supporting learning. Furthermore, teachers are focusing solely on keeping up with the prescribed pacing although they doubt that average and slower learners are learning at that pace. These learners are being left behind and excluded from acquiring the elaborated pedagogic code, its abstract orientation to meaning, and the specialization of their identity. It is highly possible that the current curriculum reform will fail to produce the desired social justice and equity in performance.

Keywords: pedagogic code, pedagogic discourse, pacing, sense-making

... the pacing rule carries invisible social class assumptions which act selectively on those who can acquire the dominant pedagogic code of the school through the distributive consequences of the visible pedagogy's strong pacing and its regulation of the deep structure of sociolinguistic competences (Bernstein, 2004, p. 207) 


\section{Introduction}

There is sufficient evidence to suggest that post-apartheid curriculum reform has failed to produce the desired higher performance for the majority of South African learners. This does not mean that there are not some successes as Maboya (2017), has reminded us. Hoadley (2018, p. 6) notes that "the vast majority of the 12.4 million pupils . . . are failed by the dual system of schooling [and that] significant racial disparities in schooling outcomes are still prevalent in the system." She went on to explain that "around $80 \%$ of schools serve poor black communities and produce very weak outcomes, and $20 \%$ are mostly former white and currently multiracial, middle-class schools that produce good outcomes."

Research on classroom practice in curriculum reforms preceding the current CAPS showed very slow pacing of knowledge as a cause of poor performance (Hoadley, 2018; Reeves, 2005; Taylor, 2009). A striking feature of most South African classrooms is the snail's pace at which teachers progress through the curriculum, sometimes reading only two or three sentences or talking about two or three mathematics problems (Taylor, 2009). Taylor pointed out how time is wasted: teachers do not arrive on time, if they arrive at all; and learners do not arrive in class on time. Once in class, teachers do not do much teaching and when they do the pace is very slow since they work at the level of the slowest learner. Reeves (2005) found that $47 \%$ of her sample of 24 poor socio-economic status (SES) schools experienced a pedagogical approach in which the pace set was very loosely bounded and appeared unconstrained by curriculum expectations.

In addition to slow pacing Hoadley (2018) has highlighted the undifferentiated pacing in her study of a foundation phase classroom. For her, "The pacing was an outcome of a pedagogy that treated the class as a homogenous whole and pegged pacing at the pace of the slowest student" (p. 192). In the same book, Hoadley also noted a communalizing orientation to instruction through which the teacher works with the whole class as a homogenous group, with little or no differentiation of tasks or attention to individual performances. She confirmed the findings of earlier studies (Hoadley, 2012; Taylor, 2009) that the slow undifferentiated pacing is characteristic of many South African classrooms.

Research on the implementation of CAPS as a new curriculum has revealed serious unintended effects. Maddock and Maroun (2018), for example, found that officials were ignoring teaching and learning and were focussing on checking teachers' files. (I will return to the implications of this point presently.) Although the pacing prescribed in CAPS was intended to guide teachers so that the grade level curriculum could be completed, Moodley (2013) reported that the teachers in her study found the pace advocated in the curriculum in most subjects to be too fast for learners. She found that educators thus rushed through the syllabus in order to complete the content and, in so doing, did not spend much-needed time with slower learners. This means that the slow pacing of the curriculum by teachers leads to much of the prescribed curriculum not being taught and this, in turn, leads to knowledge gaps in later grades. 
In line with international policy on greater regulation of teachers' work, the current CAPS (2011) prescribes content, sequencing, as well as pacing and evaluation of knowledge.

Prescriptions include topic allocation per term, lesson planning, allocation of time to a lesson, sequencing and pacing, and the number and frequency of assessments. CAPS for Grade 10 geography, by way of an example, specifies 36 hours for the topic on the atmosphere and then breaks down the time further for each sub-topic. For the sub-topic on the composition and structure of the atmosphere five hours are specified. Teachers' guides repeat the expected time for each unit and topic.

The Gauteng Department of Education has developed an Annual Teaching Plan (ATP) for all grades that indicates the percentage of content to be covered, the percentage the teacher covers, educators' remarks, and HOD's remarks (see Table 1).

Table 1: Excerpt from Grade 10 Geography Annual Teaching Plan Year: 2019.1

\begin{tabular}{|c|c|c|c|c|c|c|}
\hline $\begin{array}{l}\text { Week } \\
\text { ending }\end{array}$ & $\begin{array}{l}\text { Grade } 10 \\
2019 \text { term } 3 \\
\text { Content/activity }\end{array}$ & $\begin{array}{l}\% \\
\text { covered }\end{array}$ & $\begin{array}{l}\text { Geographical } \\
\text { skills and } \\
\text { techniques }\end{array}$ & $\begin{array}{l}\% \\
\text { covered }\end{array}$ & $\begin{array}{l}\text { Educator's } \\
\text { remarks }\end{array}$ & $\begin{array}{l}\text { HOD's } \\
\text { remarks }\end{array}$ \\
\hline $\begin{array}{l}\text { Week } 27 \\
12 \text { to } 16 \\
08 / 2019\end{array}$ & $\begin{array}{l}\text { Population } \\
\text { Movements } \\
\text { (Using cases to } \\
\text { illustrate topics } \\
\text { below is essential) } \\
\text { Temporary and } \\
\text { permanent } \\
\text { movements } \\
\text { including: migrant } \\
\text { labour, economic } \\
\text { migrants, political } \\
\text { migrants and } \\
\text { refugees } \\
\text { Attitudes to } \\
\text { migrants and } \\
\text { refugees }\end{array}$ & $77.8 \%$ & $\begin{array}{l}\text { Interpreting } \\
\text { graphs, } \\
\text { population } \\
\text { pyramids, } \\
\text { photographs and } \\
\text { models }\end{array}$ & & & \\
\hline
\end{tabular}

Given the detailed prescriptions of pacing in CAPS and the ATP, in this study I analysed pedagogic discourse and code as well as how teachers interpret and enact pacing prescriptions in the classroom in the mediation of knowledge. While, as mentioned above, research on CAPS shows that teachers rush through the syllabus in order to complete the content and do not spend enough time with slower learners (Moodley, 2013), there is a dearth of knowledge about the impact of strong pacing on knowledge codes transmitted in the classroom via pedagogic discourse. In this study, I sought to investigate the effect of the new pacing specifications on pedagogic code, pedagogic discourse, and teachers' experiences of the new pacing regime.

1 The document the teacher was using was not dated. 


\section{Strong pacing and social class}

Bernstein (2004 p. 206) has argued that pacing carries invisible social class assumptions that regulate children's consciousness differentially and invidiously according to their social class origin. Pacing specialises time, text, and space for the specialisation of consciousness of learners in terms of the official pedagogic code mediated by teachers. Bernstein has explained the connection between pacing rules and the economy of pedagogic discourse. While pedagogic discourse entails the embedding of the instructional discourse (conceptual knowledge and skills to be acquired) in a regulative discourse (character, conduct, manner), in this article I focus only on the instructional discourse in pedagogic discourse.

For Bernstein (2000) pacing is an attribute of framing, a concept that could be used to analyse pedagogy. Framing refers to the nature of control over the selection of knowledge, its sequencing, its pacing, and its evaluation criteria. Pacing refers to the expected rate of acquisition or the rate at which learning is expected to occur. Pacing is linked to sequencing of knowledge that regulates the progression of knowledge transmission that might vary the speed of the transmission. Essentially, pacing is the time allowed for learning the content. Strong pacing would be indicated by the teacher exercising explicit control over the time allocated to learning lesson topics and concepts while weak pacing would allow learners greater control over this time. Weaker pacing is, therefore, more responsive to learners' rate of learning.

Bernstein (2004) has analysed the invisible social class assumptions that underpin strong pacing of knowledge. First, the strong pacing of the academic curriculum of the school is based on the ideal of the middle-class learner who has access to two sites of acquisition-the home and the school. The school's academic curriculum cannot be acquired wholly in the time allocated to it in school, so time at school must be supplemented by official pedagogic time at home. For this, an official pedagogic discipline in the home is required. But, in the homes of the poor an official pedagogic space, a silent space, is not available. Time also may not be available given the time taken up by paid employment, taking care of children, and doing household chores. Without a second pedagogic site, acquisition will not be possible, and failure is inevitable. Strong pacing thus privileges middle-class learners who have both these sites of acquisition.

Second, strong pacing affects the transmission of the elaborated code of the school. Where the school draws on working-class or poorer learners it will adopt strategies or have strategies forced upon it that will affect both the content and the pacing of the transmission. The content is likely to stress operations-local skills rather than the exploration of principles of the subject, its internal conceptual interconnections, and its abstract, general skills. Where pacing is strong, a lexical pedagogic code in which one-word answers, or short sentences relaying individual facts/skills/operations is more likely. This pedagogic code, according to Bernstein (2004) is more typical of the school class of marginal, working-class, or poorer learners. A syntactic pedagogic code relaying relationships, processes, and connections may be more typical of the school class of middle-class children. 
The following table that shows Bernstein's (2000) distinction between restricted and elaborated pedagogic codes (cited in Taylor, 2009) has been further adapted for this study.

Table 2: Restricted and elaborated pedagogic codes

\begin{tabular}{|l|l|l|}
\hline Code & Restricted code & Elaborated code \\
\hline Common term & Everyday language & Formal language \\
\hline $\begin{array}{l}\text { Relation to } \\
\text { material base }\end{array}$ & Specific, direct & Less specific, more indirect \\
\hline $\begin{array}{l}\text { Communication } \\
\text { modality }\end{array}$ & Narrative & Analytical \\
\hline Relation to context & Context-dependent & Context-independent \\
\hline Textual attributes & $\begin{array}{l}\text { Dominantly lexical: one- } \\
\text { word answers or short } \\
\text { sentences, relaying } \\
\text { individual } \\
\text { facts/skills/operations }\end{array}$ & $\begin{array}{l}\text { Dominantly syntactic: relaying } \\
\text { relationships, processes, and connections }\end{array}$ \\
\hline $\begin{array}{l}\text { Orientation to } \\
\text { meaning }\end{array}$ & $\begin{array}{l}\text { Practical, direct relation to } \\
\text { context, narrative }\end{array}$ & $\begin{array}{l}\text { Abstract, indirect relation to context, } \\
\text { analytical }\end{array}$ \\
\hline Structure & Segmented & Inter-connected \\
\hline
\end{tabular}

The curriculum also creates a form of communication that differs from everyday communication. Unlike curriculum communication that is more analytical, everyday communication has a more narrative quality. The children of the disadvantaged classes are therefore doubly disadvantaged. There is no second site of acquisition and their orientation to language and meaning — narrative — is not valued by the pedagogic communication of the school in form or in content. Thus, the pacing of knowledge "acts selectively on those who can acquire the schools dominant pedagogic code_ elaborated and analytical" (Bernstein, 2004, p. 207).

Third, pacing impacts pedagogic discourse. With strong pacing, time is at a premium and this regulates examples, illustrations, and narratives that facilitate acquisition. Also, it regulates what questions may be put, and how many, and what counts as an explanation, both in terms of length and form. Strong pacing will tend to reduce pupils' talk and privilege teacher talk since time is scarce for transmitting the official pedagogic message.

According to Bernstein (2000), pedagogic discourse specialises time, text, and space in the classroom and in the home and enables better learning of the pedagogic code of the school; this is the basis for distinguishing oneself cognitively, socially, and culturally.

At the most abstract level, pedagogic discourse specialises time, a text and a space and brings these into a special relationship with each other. ... This level of 
specialistion of time, text and space marks us cognitively, socially and culturally (Bernstein 2000, p. 35).

While Bernstein's theory directs attention to possible effects of strong pacing, in this study I also sought to understand teacher's experiences of the strong pacing and its monitoring by management. The cognitivist framework proposed by Spillane et al., (2002) for reframing implementation research holds that implementing agents' sense of policy is influenced by their existing cognitive structures (including knowledge, beliefs, and attitudes), their situation or context, and policy signals. The cognitivist theory moves beyond a behavioral focus and foregrounds that behavioral changes have a fundamental cognitive component. Thus, the cognitive approach focuses on individual cognition, situated cognition, and policy signals. Individual cognition refers to how the individual's beliefs, values, and emotions influence the sense making process. Individuals interpret and construct new policy knowledge on the basis of their prior knowledge, beliefs, and experiences. The new ideas are subject to the danger of being seen as minor variations of what is already understood rather than as different in significant ways (Spillane et al., 2002). Situated cognition refers to how the individual agent's context is critical in shaping her or his sense of the change. A situated cognition perspective holds that the situation is constitutive of the sense making process. The third factor that shapes the implementing agent's sense of the change is policy signals. Policy signals refer to how ideas of new policy are represented and disseminated to schools and teachers. This would include what is emphasized in policy and the strategies in place for implementation and monitoring implementation of the change. The implementing agent must first notice, then frame, interpret, and construct the meaning of policy changes. Factors that contribute to policy failure include prior knowledge and sense-making; different interpretations of the same message; new ideas being seen as familiar and assimilated; understanding that may focus on superficial features and not on deeper meaning; and the values and emotions of implementing agents.

\section{Methodology}

In this paper, I report on two aspects of a larger study that examines how teachers make sense of and enact the pacing prescriptions of CAPS. First, my study considered the pacing of knowledge through the perspective of Bernstein's (2004) theory of social class and pedagogic practice. In addition to current curriculum policy prescribing strong pacing, South African syllabus coverage is strictly monitored by management and local governing districts. While strong pacing is based on the ideal middle-class learner, the South African case of school management monitoring pacing is new, and it provides a natural setting in which to test Bernstein's (2004) theory on strong pacing and its effect on pedagogic code and discourse. The second purpose of the study was to develop an understanding of teacher participants' sense of the pacing prescribed by CAPS.

Based in a qualitative research paradigm, I deemed a case study methodology to be suitable since case study enables the investigation of an issue in a specific context. This article is based on data collected at two schools within the larger study. Two low performing schools 
were purposively selected for in-depth study. These schools are in close proximity to the Johannesburg Central Business District. According to an official in the Department of Education these schools had been downgraded to underperforming status last year (2018) because of poor performance in the matric examinations.

Either I or my assistant researcher visited the schools in the study before we began to collect data. The deputy principal and a head of department (HOD) facilitated access to teachers and classrooms. The schools were very open and welcoming of us as researchers. At an initial meeting potential participants were addressed and provided with information about the study, the types of data that would be collected, and the amount of participants' time that would be required. Teachers were assured that ethical standards would be adhered to and that data would be used for research purposes only. Participants were also informed of their right to withdraw at any time without any repercussions. The participating schools' and individual participants' anonymity and confidentiality has been upheld in this article.

In both schools, learners come from surrounding very high density poorer residential areas and informal settlements. They speak isiZulu, Sotho, and Xhosa at home while English is their second language. The schools had been provided with smartboards that were being used by the teachers for power-point presentations of lessons. In both schools, homework is not given much credence as a way of increasing official pedagogic time. Homework is set regularly but very few learners do it. In one of the schools, teachers have a book in which learners who have done their homework sign. One of the teachers showed the book to me; it was blank. In the other school this homework record book was signed by two learners only.

In each school I observed three lessons of two geography teachers, or, put differently, four teachers were observed three times. The lessons were observed for me to get a sense of the pacing of knowledge, the pedagogic code being transmitted, and the extent and quality of pedagogic discourse communicated by the teacher. Lessons were audio-taped and these recordings were used in conjunction with field notes made and learning resources used in the lesson to reconstruct the lesson as it had unfolded in the classroom. During the interviews we sought to gather teachers' accounts of their experiences with reference to pacing, pedagogic code, and pedagogic discourse. The interviews would provide more data from which to infer how the school context or situated cognition affects teachers' individual sense of pacing. The interviews were audio-taped and transcribed. The interview guide was made up of openended questions that were employed flexibly during the interview process. Beyond the interview guide, we probed the teachers for more about the key aspects they brought up.

The lesson observations and interviews were transcribed. The transcript of the third lesson was selected and subjected to deductive analysis. I chose the third lesson because there was less reaction to our presence in the classroom from the teacher and the learners than had been the case during the first and second lessons. The third lesson was divided into conceptual sequences-a group of sentences that address an aspect of the topic differentiated from another conceptual sequence. For example, in one of the lessons the topic was population migration, and seven conceptual sequences were identified: what is meant by migration; 
emigration; immigration; international migration; regional migration; rural-urban migration; and forced and voluntary migration.

I analysed each conceptual sequence according to the strength of pacing (ranging from very weak to very strong), the pedagogic code it showed (ranging from restricted to elaborated), and the pedagogic discourse illustrated (ranging from extended with many examples and illustrations to restricted with no examples and illustrations). Following Bernstein (2000) an external language of description was developed to enable better analysis of the data.

According to Bernstein,

A language of description is a translation device whereby one language is transformed into another. We can distinguish between internal and external languages of description. The internal language of description refers to the syntax whereby a conceptual language is created. The external language of description refers to the syntax whereby the internal language can describe something other than itself. (pp. 135-136)

The following table illustrates the external language of description employed to analyse pacing, the pedagogic code, and pedagogic discourse of the lesson observation transcripts.

Table 3: An external language of description

\begin{tabular}{|c|c|c|c|}
\hline Concept & Conceptual derivation & Variation & Indicator \\
\hline \multirow[t]{2}{*}{ Pacing } & \multirow[t]{2}{*}{$\begin{array}{l}\text { Extent to which teacher } \\
\text { controls pacing of } \\
\text { knowledge }\end{array}$} & Stronger pacing & $\begin{array}{l}\text { The teacher controlled } \\
\text { the expected rate of } \\
\text { learning during the entire } \\
\text { lesson }\end{array}$ \\
\hline & & Weaker pacing & $\begin{array}{l}\text { The teacher and learner } \\
\text { controlled the expected } \\
\text { rate of learning during } \\
\text { the entire lesson }\end{array}$ \\
\hline \multirow[t]{2}{*}{ Pedagogic code } & \multirow[t]{2}{*}{$\begin{array}{l}\text { Extent to which the } \\
\text { pedagogic code is } \\
\text { evident }\end{array}$} & Restricted code & $\begin{array}{l}\text { Lexicalised - short } \\
\text { sentences, one-word } \\
\text { answers, context- } \\
\text { dependent, abstract } \\
\text { orientation to meaning }\end{array}$ \\
\hline & & Elaborated code & $\begin{array}{l}\text { Syntactic - relationships } \\
\text { and connections } \\
\text { established, context- } \\
\text { independent, practical } \\
\text { orientation to meaning }\end{array}$ \\
\hline $\begin{array}{l}\text { Pedagogic } \\
\text { discourse }\end{array}$ & $\begin{array}{l}\text { Extent to which } \\
\text { pedagogic discourse } \\
\text { enables learning of } \\
\text { pedagogic code }\end{array}$ & $\begin{array}{l}\text { Extended } \\
\text { pedagogic } \\
\text { discourse }\end{array}$ & $\begin{array}{l}\text { Many examples and } \\
\text { illustrations that } \\
\text { facilitate acquisition of } \\
\text { the elaborated pedagogic } \\
\text { code }\end{array}$ \\
\hline
\end{tabular}




\begin{tabular}{|l|l|l|}
\hline & $\begin{array}{l}\text { Restricted } \\
\text { pedagogic } \\
\text { discourse }\end{array}$ & $\begin{array}{l}\text { No or few examples and } \\
\text { illustrations that } \\
\text { facilitate acquisition of } \\
\text { the elaborated pedagogic } \\
\text { code }\end{array}$ \\
\hline
\end{tabular}

The analysis enabled a description of the dominant mode of pacing of knowledge, the dominant pedagogic code, and the dominant mode of pedagogic discourse in each conceptual sequence of the lessons observed. However, it did not illuminate why teachers were strongly pacing in spite of knowing that average and slower learners were not keeping up with the pace. Interview data enabled us to understand the pacing regime from the teachers' point of view. The interview transcripts were analysed in terms of the second key question: "What are teachers' views of how the new pacing regime impacts teaching and learning?"

\section{Data analysis and presentation}

\section{Pacing of knowledge in the classroom}

Pacing refers to the expected rate of acquisition, or, in other words, the rate at which learning is expected to occur. All lessons showed that pacing or the rate of expected learning is controlled by the teacher. The lessons also complied with the topics specified by CAPS that teachers were supposed to be teaching for the third term. The Grade 10 geography teacher was teaching population migration as per the CAPS requirement. This section of the topic on population is allocated 8 hours. Across the three lessons observed teachers moved briskly across the prescribed sub-topics. Similarly, the Grade 11 geography teacher was teaching the section trade and development as specified by CAPS. Both teachers had complied with syllabus coverage in terms of time and percentage or were ahead. In the lessons observed, a shift from very slow pacing to faster pacing according to CAPS specifications had occurred. One of the teachers in the study explained,

I know in the first term this is what we do because the annual teaching plan (ATP) does not change, it is the same every year, so I keep to it. That is why I am saying by the time we are about to close (at end of 3rd term) I am already on maybe $78 \%$ of the coverage for the term. So, I am always on time.

\section{Undifferentiated pacing of knowledge}

Undifferentiated pacing was observed in all lessons. Teachers addressed the whole class as a homogenous group with little or no attention to individual learning needs. Teachers assumed that all learners were learning and understanding content and concepts homogenously. They did not ask questions that would illuminate differences in understanding and learning. All learners were required to do the same tasks and exercises; generally, these were based on recall of facts. 


\section{Pedagogic code evident in the classroom}

The pedagogic code of curriculum knowledge according to Bernstein (2004) is elaborated, formal, context independent, inter-connected, analytical, syntactic, and it relays an abstract orientation to meaning. In contrast, the general pedagogic code evident in all lessons observed was severely restricted. In a Grade 11 class the question, "Why is trade important?" was dismissed with one response from a learner: "Meet each other's needs." The following excerpt from the Grade 10 geography class illustrates a lexicalised pedagogic code where one- or two- word answers or very short sentences sufficed before the teacher moved onto the next aspect.

$T$ : What is the reason for people to move?

$L:$ Job opportunities

$T$ : Yes, what are other reasons?

$L$ : Urban areas are more advanced.

$T$ : Yes, what are other reasons?

Learner responses were not further extended nor reframed by the teacher towards a syntactic pedagogic code that goes deeper into establishing taxonomic relationships and connections within the subject. The dialogue demonstrates an everyday or narrative way of communicating. Here the lack of a coherent conceptual structure and vertical and horizontal interconnections places the narrative more in the realm of common-sense knowledge.

In other lessons the teacher did reference the concepts of the elaborated code, as required by CAPS, but did not establish relationships and interconnections. The following excerpt of a Grade 11 concluding activity/exercise illustrates the key concepts being referenced and defined but not interconnected.

$T$ : What is trade?

$L:$ It is the exchange of goods.

$T$ : What is a commodity?

$L:$ It is goods traded.

$T$ : What is international trade?

$L$ : Trade across countries.

$T$ : What is a trade bloc?

$L:$ A group of countries.

$T$ : Why is trade important?

$L$ : It causes development.

The language in the above excerpt is formal and the concepts are context independent. But the discourse emulated the discrete or segmented nature of the restricted code. It did not relay the analytical structure of the topic, nor were inter-connections within and across each concept referenced. For example, the first concept, trade, could have been further classified into types of trade followed by the definition of each type and then by examples of each. Similarly, the concept of commodity could have been classified into the types of commodities 
traded followed by accepted definitions and then by examples of each type of commodity. A further aspect could have been a discussion of the general patterns in commodities traded by developed and developing countries. Such classifications, definitions, interconnections, expositions, and analyses of patterns and examples would lean more towards the elaborated code and enrich learners' understanding of the phenomenon of trade.

\section{Pedagogic discourse in the classroom}

Pedagogic discourse refers to pedagogic communication that aims to facilitate the learning of the pedagogic code. It includes explanations, narratives, examples, co-extensions of concepts, illustrations, questioning by the teacher, and identifying and correcting misconceptions. Pedagogic discourse may be extended or restricted; in these four lessons it was very restricted. Consider these excerpts from two Grade 10 lessons.

$T$ : What is overpopulation?

$L$ : Many people in an area

$L$ : Many people in an area, creating too much demand on natural resources

The teacher acknowledged the learner's response of "many people in an area" but did not provide further denotations of the concept of overpopulation and its definition in geography. In the next excerpt, note how the teacher accepts the response "profit" without any further exposition, extension, or illustration.

$T$ : What are the benefits of commercial farming?

$L$ : Profit

$T$ : What is negative about commercial farming?

$L:$ No fertile soil

$L:$ Air pollution

$L$ : Less job opportunities

In another example, a Grade 11 geography teacher transmitted to the learners a formal definition of the concept of a market without any elaboration.

$T$ : The term market is not a physical space or building but a set of systems and structures that makes international trade possible.

The definition was not analysed into its component parts to ensure the learning of new knowledge. The pedagogic discourse lacked supporting explanations, examples, illustrations, and narratives that facilitate acquisition. Examples of systems and structures that govern international trade were not given. What individual learners understood or did not understand was not evident. 
Table 4: Summary of pacing, pedagogic code, and pedagogic discourse in the third lesson of the four teachers

\begin{tabular}{|l|l|l|l|l|}
\hline $\begin{array}{l}\text { Analytical } \\
\text { criteria }\end{array}$ & $\begin{array}{l}\text { Lesson 3 Teacher } \\
\text { A (no. of } \\
\text { sequences } \\
\text { analysed }=7)\end{array}$ & $\begin{array}{l}\text { Lesson 3 } \\
\text { Teacher B (no. } \\
\text { of sequences } \\
\text { analysed = 9) }\end{array}$ & $\begin{array}{l}\text { Lesson 3 Teacher } \\
\text { C (no. of } \\
\text { sequences } \\
\text { analysed = 8) }\end{array}$ & $\begin{array}{l}\text { Lesson 3 Teacher } \\
\text { D (no. of } \\
\text { sequences } \\
\text { analysed = 9) }\end{array}$ \\
\hline Pacing & $\begin{array}{l}\text { Very strong - } \\
\text { teacher set the } \\
\text { pace in all 7. }\end{array}$ & $\begin{array}{l}\text { Very strong - } \\
\text { teacher set the } \\
\text { pace in all 9 }\end{array}$ & $\begin{array}{l}\text { Very strong - } \\
\text { teacher set the } \\
\text { pace in all 8. }\end{array}$ & $\begin{array}{l}\text { Very strong - } \\
\text { teacher set the } \\
\text { pace in all 9. }\end{array}$ \\
\hline Pedagogic code & $\begin{array}{l}\text { Lexical } \\
\text { restricted }\end{array}$ & $\begin{array}{l}\text { Lexical } \\
\text { restricted }\end{array}$ & $\begin{array}{l}\text { Lexical } \\
\text { restricted }\end{array}$ & $\begin{array}{l}\text { Lexical } \\
\text { restricted }\end{array}$ \\
\hline $\begin{array}{l}\text { Pedagogic } \\
\text { discourse }\end{array}$ & $\begin{array}{l}\text { Restricted }- \text { no } \\
\text { examples }\end{array}$ & $\begin{array}{l}\text { Restricted }- \text { no } \\
\text { examples }\end{array}$ & $\begin{array}{l}\text { Less restricted - } \\
\text { one example }\end{array}$ & $\begin{array}{l}\text { Restricted - } \\
\text { no examples }\end{array}$ \\
\hline
\end{tabular}

\section{Emergent themes from teacher interviews}

\section{Strategies to keep up with the prescribed pacing}

All four teachers revealed that they do not cover the prescribed curriculum fully. A few common strategies were employed that undermine coverage of the full prescribed curriculum. The first strategy was teaching according to exam guidelines and not those of the curriculum as one teacher disclosed.

Interviewer (I): What do you do if you are behind the ATP?

$T$ : Teach what is in the exam guidelines and leave out other sections to avoid learners complaining that they were not taught what came out in the exams.

Another teacher felt confident to disclose that she teaches what is in the exam guidelines because the HOD advised them not to focus on sections that are not in these.

The second strategy was not teaching every aspect in the curriculum or asking learners to do it on their own.

$T$ : I don't teach everything. I leave out sections or ask learners to do it themselves.

\section{Extra lessons after official school time}

Time at school must be supplemented by official pedagogic time at home to meet Bernstein's (2004) recommendation of two sites of acquisition, as pointed out earlier in this article. For these teachers the official time during the school day was not enough to cover the topics prescribed. Teachers did not set homework, as I have explained, because the learners did not do it. Teachers were thus teaching after the official school day for 45 minutes 2 days a week so that they could cover the content. 
Teachers have differentiated extra lessons for syllabus coverage for matric classes from extra lessons in Grade 10 and 11 to enable learners to keep up with the ATP. The extra lessons were not pedagogically motivated to facilitate acquisition but to catch up with the pacing required in the ATP. Teachers also indicated that they have other priorities such as focusing on extra classes for matric learners, marking learner's work, and sports duties that distract from the extra lessons for learners. One of the teachers disclosed that while she does give extra lessons, she finds it very difficult to do so given that she has to mark learners' work.

I: Are the extra lessons enabling teaching and learning?

$T$ : I do the extra lesson classes but sometimes I do not get enough time. I have to mark as well as prepare for the extra time when I have not finished the ones outlined in the ATP.

Another teacher informed me that he taught to cover the syllabus for matric classes during the extra lessons in the morning before the official school day and then had an extra class in the afternoon.

$T$ : We used to have extra lessons, but it was just for Grade 12 . We needed to cover the syllabus within two terms, so we used to have morning classes. For afternoon classes I gave them extra lessons.

It was clear that teachers complied with the practice of extra lessons because they were required to account in writing for what they had done to keep up with the ATP.

\section{Teachers' sense of pacing}

The teacher participants' sense of the new policy is that it is essential to maintain the required pace. A number of official documents emphasise, by way of repetition, the pacing as required by CAPS. The "Grade 10 Geography annual teaching plan" (Gauteng Department of Education, 2019) tabulates Grade 10 content and activity per week and then, in another column, demands details of the percentage covered. The column for geographical skills and techniques is also followed by percentage covered, and then there are two columns, one for the educator's remarks and one for the HOD's remarks. All this is repeated in teacher guides and the ATP. School districts have another document that tabulates content to be covered per week per term, the number of hours to be spent on that content, the percentage completed, the number of activities to be done and the date of completion. The schools have operationalised the monitoring of the required pacing. Adherence to prescribed CAPS pacing has been enforced by hierarchical management structures in schools via monitoring tools (forms that have to be completed). The extent to which pacing, and school-based assessment is being followed by teachers is tracked first by each individual teacher in a form entitled "Educator reporting tool for work schedule and school-based assessment (SBA) completion." Two aspects, percentage syllabus completion and percentage SBA completion, are tracked. Thus, one teacher's completed forms for the first term showed $23.9 \%$ of the syllabus and $25 \%$ SBA completed. Second, pacing by teachers and SBA completion is then tracked by the HOD using an HOD monitoring tool (also a form) in which another reporting tool for work 
schedule and SBA completion is used. In this form the following aspects are tracked and questions answered by the HOD under various headings: verified percentage of syllabus completion; verified percentage of SBA completion; names of learners whose books were checked; verify support given to learners; comment on quality of feedback to learners; is there synergy between work schedules, lesson plans, SBA, and learners work; support given to teacher and strategies to improve learner performance. This form is then given to the principal who is accountable to district officials. In a surprise visit, district officials, using a phase monitoring tool, monitor the selected teacher and the HOD. The HOD is checked on 17 items under curriculum management including annual teaching plan, programme of assessment, educators' file, curriculum coverage, and evidence of completed monitoring tools. The selected educator's file, assessment records, learners' books and content coverage are checked. The names of learners whose books have been checked must also be recorded.

All the teachers interviewed strive to comply with pacing as prescribed by policy. The main talk among teachers is about keeping up with the prescribed pace, completing the forms required by the HOD, and the extra lessons they plan to do to catch up with the prescribed pace. On the days of data collection teachers' discussions in the staffroom revolved around pacing, where they were, and their plans to catch up. Teachers indicated that their main focus was on keeping up with the pace because this is what the HOD checks. Thus, situated cognition supports teacher's individual cognition that pacing must be complied with.

\section{Anxiety of teachers that learners may not be understanding}

All the teachers expressed concern and anxiety that learners were not understanding what was being taught and that some learners needed more time to understand the content. I quote two typical responses here.

I: Does the pace of your lesson enable teaching and learning?

$T$ : The pace I have to follow does not cater for the needy majority. Some learners are able to keep up, but some are left behind. So, it does not really consider the learners left behind.

$T$ : I think in terms of the time, it disadvantages the learner at the end of the day because we have different types of learners in the classroom. If the teacher is expected to have finished a certain topic within a specific period of time the teacher finishes it but there are learners who did not understand.

Teachers were concerned that learners may not have grasped the content they had been teaching. Again, I offer two similar responses from teachers.

I: Have you been able to keep up with the ATP?

$T$ : Not really, I can say yes but then in terms of learners' understanding no, because I might have done what I am supposed to cover every week, but the issue lies with learners themselves whether they grasped. So, I cannot conclusively say that I was 
able to keep up with the ATP because that is not the most important thing, but the important thing is that learners grasp the content.

$T$ : I cannot really speak on their behalf, but I can see a challenge. It is quite difficult for them to keep up. Some learners are able to keep up, but most are left behind. So, it does not really consider the learners left behind.

Teachers revealed that they teach as if all learners are at the same level. This reply was in keeping with those of the other teachers.

$T$ : In reality we no longer have freedom to make sure learners understand. We are teaching as if all learners are at the same level. Learning is no longer authentic.

Teachers disclosed that HODs seem only to be monitoring pacing. One of the teachers was asked what kind of support she gets from her HOD.

$T$ : Managing time, keeping up to time, because to them (management) time is everything ... a as a teacher you have to push but at the same time learners seem not to understand. We are under pressure. Another challenge is [that] learners' cognitive level is not the same; some need more time than others.

Management of teachers has been reduced to checking whether coverage has been achieved and they are policed to cover the content in time or give extra lessons. The extra lessons are motivated by the coverage demands and not support for learning. A teacher's words reveal her concerns about the focus of management on monitoring teachers only.

$T$ : Monitoring ... a teacher is given an ATP ... most of the time the HODs come check. They have a reporting tool. They give you the topics and then you have to tell them where you are, compile own report. The DPs do the same. Go to the district. How far are the teachers? HODs and DPs [are] worried about stats and submissions.

\section{Discussion}

The teacher participants' sense of the pacing specifications of CAPS is the need to comply with the expected pace although they are aware that learners are not learning at the required pace. The main policy signal to teachers is that pacing is paramount. This individual sense of policy is corroborated by the situational context sense and because CAPS signals pacing as superordinate. Pacing is one of the policy requirements of CAPS that has been operationalised for accountability purposes into forms that require teachers to provide details of the percentage of the syllabus completed and, should they be behind, to say what they are doing to catch up. The general discourse of teachers focusses on pacing because teachers perceive HODS as focussing on pacing only. The regular monitoring of pacing by the HOD, deputy principal, principal, and government district officials reinforces the teachers' sense that pacing is paramount. Consistent with researchers on CAPS implementation (Maharajh, Nkosi, \& Mkhizi, 2016; Moodley, 2013) teachers find the strong pacing is not in the interest 
of all learners. This study confirms Maddock and Maroun's (2018) findings that officials are ignoring teaching and focusing only on checking teachers' files and learners' books. Teachers' individual and situated cognition align with policy signals to make pacing of knowledge more important than learning.

Teachers' conception of these pacing requirements affects their pedagogic discourse. Because it is pedagogic discourse that mediates the pedagogic code, learners' access to the pedagogic code is severely compromised. The teachers in this study not only mediated a lexicalised pedagogic code but also provided very few or no examples to facilitate acquisition. This reflects what Hoadley (2018, p. 13) refers to as "schooling without learning." The findings of this study concur with the point made by Ramatlapana and Makonye (2012) that the prescriptive nature of CAPS has not only compromised teacher autonomy but has also affected the quality of learning.

The undifferentiated strong pacing means that average and slower learners are denied access to the elaborated pedagogic code. In contrast with earlier research accounts of teachers pacing to the slowest learner (Hoadley, 2018; Reeves 2005; Taylor 2009), teachers in the study were pacing knowledge according to CAPS policy. Furthermore, the lack of differentiated pacing that would provide support for individual learning difficulties diminishes learning opportunities for slower learners. The pedagogic code is further diluted by the teachers' leaving out conceptual content that will not be assessed in the examination instead of teaching the entire curriculum.

The rapid pace of the curriculum has a deleterious impact on teaching and learning. Teachers have complied with the new pacing regulations so that the prescribed coverage of the curriculum is adhered to. The teachers in the study reported feeling coerced into complying with prescribed pacing in a mechanical manner and they were anxious that not all learners were learning at the pace being maintained.

This qualitative study corroborates Moodley's (2013) conclusion that teachers found the pace advocated in the curriculum in most subjects to be too fast for learners. It also appears to provide evidence for Bernstein's (2004) theory that stronger pacing impacts pedagogic discourse. The lexicalised pedagogic code taught compromises acquisition of the elaborated code, which is the basis of a specialised consciousness. While the school timetable is being supplemented by extra lessons after school, many factors render the practice ineffective. Like classroom practice, the focus is on the coverage of content and not on supporting learning. Teachers admit they do not give the extra lesson the same attention because of the pressure of other work such as marking and preparing for the next day. Furthermore, the teachers in this study came to the conclusion that homework is futile since the learners do not do it. This means that there is no extension of official pedagogic time in the home, the second site necessary for the pedagogic specialisation of learners' consciousness. 


\section{Conclusion}

In this study, I focussed on how the pacing regime advocated by CAPS impacts the pedagogic code and pedagogic discourse in twelve geography lessons as I tried to understand the teachers' sense of how the new pacing regime impacts teaching and learning. The strong pacing of knowledge has unintended consequences; the pedagogic code is lexicalised and hence impoverished and pedagogic discourse contains far too little elaboration to facilitate acquisition for slower learners. The curriculum policy on pacing and hierarchical monitoring of enactment of pacing distracts teachers from the pedagogic goal of supporting learning. Furthermore, teachers are focusing solely on keeping up with the prescribed pacing although they doubt that average and slower learners are learning at that pace. All teachers in the study foregrounded keeping up with the strong pacing prescribed in CAPS and the ATP. Teachers are concerned that not all learners are keeping up but keep to the prescribed pacing because it is monitored by the HOD, the deputy principal, the principal, and district officials. Average and slower learners are not taught in differentiated ways to support their learning since time is limited and weakening the pacing would lead to falling behind the ATP.

Although CAPS is a knowledge-based curriculum that has corrected the supposed evacuation of content in prior reforms, the fact that there is a clear strategy for implementation and monitoring of pacing exclusively, makes this the key policy signal. Changes in pacing alone are insufficient to enable pedagogic instructional discourse that will facilitate acquisition of the elaborated discourse of the curriculum. Thus, the words of one of the teachers, in suggesting that the curriculum needs revision again, sound prudent.

CAPS needs to be revised again and scrutinised and checked [to see] if it is serving the needs of the learners or someone else's needs, especially [in terms of] the organisation of the content learners are expected to learn in a short period of time and teachers are expected to teach and assess within [that same] short period of time.

This case study shows that most of the learners in the study are being left behind and excluded from acquiring the elaborated pedagogic code along with its abstract orientation to meaning, as well as the specialization of their identity. If the findings of this case study are more widespread in other similar contexts, it is highly possible that the current curriculum reform will fail to produce the desired social justice and equity in performance.

I am grateful to the peer reviewers and the editor of this issue of the journal for insightful and constructive suggestions on how to strengthen this article. I also acknowledge and thank the teachers who participated in the study. All opinions, findings, interpretations, and conclusions expressed in this article are mine and do not reflect the views of my department.

\section{References}

Bernstein, B. (2000) Pedagogy, symbolic control and identity: Theory, research, critique. Oxford, UK: Rowman \& Littlefield. 
Bernstein, B. (2004). Social class and pedagogic practice. In S. J. Ball (Ed.), The RoutledgeFalmer reader in sociology of education (pp. 196-218). London, UK: RoutledgeFalmer.

Department of Basic Education. (2011). National Curriculum Statement (NCS). Curriculum and Assessment Policy Statement (CAPS). Further Education and Training Phase: Geography Grade 10-12. Pretoria, RSA: Author.

Hoadley, U. (2012). What do we know about teaching and learning in SA primary schools? Education as Change, 16(2) 187-201. http://dx.doi.org/10.1080/16823206.2012.745725

Hoadley, U. (2018). Pedagogy in poverty. London, UK: Routledge.

Maddock, L., \& Maroun, W. (2018). Exploring the present state of South African education: Challenges and recommendations. South African Journal of Higher Education, 32 (2), 192-214. https://doi.org/10.20853/32-2-1641

Maharajh, L., Nkosi, T., \& Mkhize, M. C. (2016). Teachers experience of the implementation of the Curriculum and Assessment Policy Statement (CAPS) in three primary schools in KwaZulu-Natal. Africa's Public Service and Delivery Performance, 4(3), 371-387.

Maboya, M. J. (2017, February 28). Progress on the implementation of the curriculum and assessment policy statement (CAPS). Paper presented to the Portfolio Committee on Basic Education. Pretoria, RSA. Retrieved from pmg-assets.s3-website-eu-west1.amazonaws.com > 170228CAPS

Moodley, G. (2013) Implementation of the Curriculum and Assessment Policy Statement: Challenges and implications for teaching and learning (Unpublished master's thesis). University of South Africa, Pretoria, RSA.

Spillane, J. P., Reiser, B. J., \& Reimer, T. (2002) Policy implementation and cognition: Reframing and refocusing implementation research. Review of Educational Research, 72(3), 387-431. https://doi.org/10.3102/00346543072003387

Ramatlapana, K., \& Mkonye, P. (2012) From too much freedom to too much restriction: The case of teacher autonomy from NCS to CAPS. Africa Education Review, 9(1), 7-25. https://doi.org/10.1080/18146627.2012.753185

Reeves, C. (2005, April). Can schools reverse social disadvantage by pedagogy or opportunity to learn? Paper presented at the Consortium for Research on School Quality seminar, Johannesburg, RSA.

Taylor, N. (2009). The state of South African schools Part 1: Time and the regulation of consciousness. Journal of Education, 46, 11-32. 